\title{
Dinitrophenyl hapten with laser immunotherapy for advanced malignant melanoma: A clinical study
}

\author{
DIAN-JUN CHEN ${ }^{1 *}$, XIAO-SONG LI $^{1 *}$, HUI ZHAO $^{1}$, YAN FU $^{1}$, HUAN-RONG KANG ${ }^{1}$, \\ FANG-FANG YAO ${ }^{1}$, JIA HU ${ }^{1}$, NAN QI ${ }^{1}$, HUAN-HUAN ZHANG ${ }^{1}$, NAN DU ${ }^{1}$ and WEI-R CHEN ${ }^{2}$ \\ ${ }^{1}$ Department of Oncology, First Affiliated Hospital of The Chinese People's Liberation Army General Hospital, Beijing 100048, \\ P.R. China; ${ }^{2}$ Department of Engineering and Physics, University of Central Oklahoma, Edmond, OK 73034, USA
}

Received March 19, 2015; Accepted August 25, 2016

DOI: $10.3892 / \mathrm{ol} .2016 .5530$

\begin{abstract}
The present study aimed to evaluate the efficacy and safety of in situ immunotherapy with dinitrophenyl (DNP) hapten in combination with laser therapy for patients with malignant melanoma (MM). Between February 2008 and March 2012, 72 patients with stage III or IV MM were enrolled. Patients received in situ DNP alone $(\mathrm{n}=32)$ or in combination with laser therapy $(n=32)$, and each group received dacarbazine chemotherapy. The levels of peripheral cluster of differentiation $(\mathrm{CD}) 4^{+} \mathrm{CD} 25^{+}$regulatory $\mathrm{T}$ cells (Tregs), interleukin (IL)-10 and tumor growth factor (TGF)- $\beta$ were detected by ELISA. The association between delayed-type hypersensitivity (DTH) and survival time was evaluated. Although peripheral Treg levels significantly decreased over time in the two groups $(\mathrm{P}<0.001)$, there was no significant difference between the treatment groups $(\mathrm{P}=0.098)$. Patients receiving the combination treatment exhibited significantly higher interferon- $\gamma$ production by $\mathrm{CD}^{+}$and $\mathrm{CD}^{+}{ }^{+} \mathrm{T}$ cells (both $\mathrm{P}<0.001$ ), as well as significantly reduced levels of IL-10, TGF- $\beta 1$ and TGF- $\beta 2$. In addition, patients in the combination treatment group experienced significantly longer overall survival $(\mathrm{OS} ; \mathrm{P}=0.024)$ and disease-free survival (DFS; $\mathrm{P}=0.007$ ) times; a $\mathrm{DTH}$ response of $\geq 15 \mathrm{~mm}$ was also associated with increased OS time and DFS time $(\mathrm{P} \leq 0.001)$. Finally, no severe adverse events were observed in either treatment group. Overall, in situ immunization with DNP in combination with laser immunotherapy may activate focal $\mathrm{T}$ cells, producing a regional antitumor immune response that increases cell-mediated immunity and improves survival in MM patients. Thus, this may represent a novel
\end{abstract}

Correspondence to: Dr Nan Du, Department of Oncology, First Affiliated Hospital of The Chinese People's Liberation Army General Hospital, 51 Fucheng Road, Haidian, Beijing 100048, P.R. China

E-mail: nandu991@yeah.net

*Contributed equally

Key words: malignant melanoma, metastasis, tumor immunity, dinitrophenyl, contact dermatitis, laser therapeutic strategy for patients with unresectable, advanced MM.

\section{Introduction}

Derived from neural crest cells, malignant melanoma (MM) accounts for $\sim 1.5 \%$ of all tumors and is the cutaneous malignancy with the highest mortality rate (1). There are $>10$ million new cases of MM diagnosed every year (1). In total, $21 \%$ of MM patients present with focal skin metastasis and $50 \%$ with regional lymph node metastasis (1). MM patients with distant metastasis (stage IV) usually have poor prognoses, with a median survival time of 5-8 months, and the $\geq 5$-year survival rate is $<2 \%$ (2). With social and economic development, the incidence of MM is increasing each year (3).

The poor prognosis of MM patients is reflective of the lack of an effective therapy. Systemic chemotherapy, including mono- and poly-chemotherapies, immunomodulatory therapies and vaccination therapy with dendritic cells (DCs) or genetically modified tumor cells, remains controversial (2). Although there is evidence showing that the combined use of interleukin (IL)-2, interferon (IFN) and chemotherapeutics may achieve a response rate as high as $64 \%(4,5)$, the efficacy of systemic therapy remains disappointing; systemic monotherapy usually achieves a clinical response rate of $<15 \%$ (6-10). However, prospective, randomized clinical trials have shown no evidence that other drugs are superior to dacarbazine (DTIC) for MM patients (10). Thus, it is imperative to identify an alternative therapeutic strategy to improve the prognosis of metastatic MM patients. Although MM is highly malignant and insensitive to chemotherapy and radiotherapy, it maintains high immunogenicity (11). Thus, immune therapy may serve as a strategy for advanced MM. However, a hapten-modified cellular vaccine for melanoma, MVAX ${ }^{\circledR}$, has stalled in clinical development due to manufacturing and regulatory problems (11).

Dinitrophenyl (DNP) is a classic hapten used to induce contact-related delayed-type hypersensitivity (DTH) due to its potent antigenicity and high absorption in healthy skin. DTH is an allergen-induced, $\mathrm{T}$ cell-mediated immune response that can evaluate the cellular immunity in humans (12). However, clinical studies $(11,13)$ have shown the limited success of immune therapy, which is partially ascribed to the limited 
availability of polypeptides that restrict major histocompatibility complex (MHC) class II presentation and subsequent induction of tumor-specific cluster of differentiation (CD) $4^{+}$ $\mathrm{T}$-cells. In addition to suppression of antigen presentation as well as secretion of immunosuppressive molecules by tumor cells, regulatory $\mathrm{T}$ cells (Tregs) in the tumor may also inhibit the antitumor immune response $(14,15)$, representing a major barrier in antitumor immune therapy (16). Tregs may inhibit the proliferation of effector $\mathrm{T}$ cells, including $\mathrm{CD} 4{ }^{+} \mathrm{CD} 25$ $\mathrm{T}$ cells and $\mathrm{CD} 8^{+}$cytotoxic $\mathrm{T}$ lymphocytes, suppress the maturation and antigen presentation of dendritic cells, and alter cytokine levels $(17,18)$. Certain studies have identified increased peripheral Treg levels in patients with metastatic MM (19-23); therefore, therapies that decrease Treg levels may be beneficial for these patients.

The energy emitted by a laser may be absorbed by tissues and transformed into heat, resulting in the release and presentation of tumor antigens, and a subsequent antitumor immune response (11). Therefore, the present study tested the hypothesis that MM patients receiving localized immunotherapy to induce DTH via DNP in combination with laser therapy would have improved disease-related outcomes as compared with patients treated with DNP alone. In addition to chemotherapy, MM patients received DTH alone or with concomitant laser therapy, and the extent of DTH, as well as the overall survival (OS) times of the patients, were determined. In addition, the levels of peripheral $\mathrm{CD} 4{ }^{+} \mathrm{CD} 25^{+}$Tregs, IFN- $\gamma$-producing $\mathrm{CD} 8^{+} \mathrm{T}$ cells and $\mathrm{CD} 4^{+}$cells, IL-10, and tumor growth factor (TGF) $-\beta$ were detected. The combination of immunotherapy with laser therapy may represent a novel therapeutic strategy for patients with unresectable, advanced MM.

\section{Materials and methods}

Patients. A total of 72 patients with stage III (b or c) or IV (unresectable) MM, according to the American Joint Committee on Cancer staging system (24), were recruited from the First Affiliated Hospital of the Chinese People's Liberation Army (PLA) General Hospital (Beijing, China) between February 2008 and March 2012 (Table I). The following inclusion criteria were employed: i) A pathological diagnosis of MM; ii) normal liver and kidney function, as well as normal results from a routine blood test; iii) a Karnofsky score of $\geq 60$ (25); iv) an estimated survival time of $>3$ months; and v) the presence of unresectable MM (cutaneous MM with local or distant metastasis). Therapeutic efficacy was evaluated with the Response Evaluation Criteria in Solid Tumors (26). The present study conforms to the provisions of the Declaration of Helsinki (2000 revision). Informed consent was obtained from each patient, and the study was approved by the Ethics Committee of the First Affiliated Hospital of the Chinese PLA General Hospital. The clinicaltrial.gov identifier number of the study is NCT02372708.

Prior to immunotherapy, the medical history of each patient was completely reviewed, a physical examination was performed, ultrasonography was undertaken to examine the lymph nodes of the groin, armpits and neck, and cranial magnetic resonance imaging and chest/abdominal computed tomography were performed. The patients were re-examined at 3 months post-therapy, and subsequent evaluations were performed once every 3 months thereafter. Adverse events were graded according to the criteria described in the Common Terminology Criteria for Adverse Events, version 4.0 (27).

Treatment. All the patients received DTIC-based chemotherapy. Once all the physical and laboratory examinations were performed, treatment with DTIC $\left(200 \mathrm{mg} / \mathrm{m}^{2}\right.$; Nanjing Pharmaceutical Factory Co., Ltd., Nanjing, China) was initiated and performed once every 3 weeks for a total of 5 courses. When disease progression became evident, the therapy was discontinued. When stable disease or disease improvement was observed, the chemotherapy was continued. Chemotherapy was administered over a median of 5 courses (range, 2-36 courses). In the combination therapy group, 36 patients received DNP (Sinopharm Chemical Reagent Co., Ltd., Shanghai, China) with focal laser therapy. For the combination therapy group, diluted DNP-vaseline (2\% DNP in $0.1 \mathrm{ml}$ vaseline) was applied on the primary or metastatic lesions on the first day after chemotherapy in each course, and the lesions were concurrently irradiated with a laser for $10 \mathrm{~min}$ at $1 \mathrm{~W} / \mathrm{cm}^{2}$ and then dressed. After 2 days, the presence of contact dermatitis was confirmed. If the lymph nodes were resected, sensitization was performed at the occipital region (2x2-cm area) once weekly (28). In the control group, 36 patients received DNP alone. Monotherapy consisted of the application of DNP-vaseline on the lesions; the remaining treatments were similar to the combination therapy group.

Prior to chemotherapy and at 2, 5, 10 and 20 days after in situ immunization, fasting venous blood was collected $(10 \mathrm{ml})$ from all the patients and divided into two parts. One part was centrifuged $\left(600 \times g ; 5 \mathrm{~min} ; 4^{\circ} \mathrm{C}\right)$, and the resultant serum was collected and stored at $-20^{\circ} \mathrm{C}$ for the detection of cytokines; the other part was anti-coagulated with heparin, and peripheral blood mononuclear cells (PBMCs) were separated by density gradient separation with lymphocyte separation medium (Sinopharm Chemical Reagent Co., Ltd.). The PBMCs were counted, and cell density was adjusted to $1-2 \times 10^{6}$ cells $/ \mathrm{ml}$ and analyzed by flow cytometry.

Flow cytometry. Using PBMCs, $\mathrm{CD} 8^{+}$and $\mathrm{CD} 4^{+} \mathrm{T}$ cells were screened separately with $10 \mu 1 / 10^{7}$ cells of anti-CD8 monoclonal antibody magnetic Dynabeads (Life Technologies; Thermo Fisher Scientific, Inc., Waltham, MA, USA) and anti-CD4 monoclonal antibody magnetic MicroBeads (Miltenyi Biotec $\mathrm{GmbH}$, Bergisch Gladbach, Germany). Once the beads were removed, the $\mathrm{CD} 8^{+}$and $\mathrm{CD} 4^{+} \mathrm{T}$ cells were blocked using blocking reagents (eBioscience, Inc., San Diego, CA, USA) for $30 \mathrm{~min}$ at $4^{\circ} \mathrm{C}$, and independently labeled with $10 \mu 1$ of each antibody against CD4-fluorescein isothiocyanate (FITC) (mouse monoclonal; catalogue no. 11-0047-42), CD8-FITC (mouse monoclonal; catalogue no. 11-0088-42) and IFN- $\gamma$-phycoerythrin (PE) (mouse monoclonal; catalogue no. 12-7319-42) (eBioscience, Inc.) in $1 \mathrm{ml}$ of staining buffer (1:100 dilution; eBioscience, Inc.). Labeled cells were detected and analyzed by a FACSCanto analyzer (BD Biosciences, Franklin Lakes, NJ, USA).

For the analysis of Tregs, the PBMCs $(100 \mu \mathrm{l})$ were also mixed with $10 \mu 1$ of FITC-conjugated mouse anti-human CD4 (eBioscience, Inc.) or PE-conjugated CD25 (eBioscience, Inc.) antibodies, followed by incubation in the dark for $30 \mathrm{~min}$ at $4^{\circ} \mathrm{C}$ Upon washing in PBS twice, $500 \mu 1$ of PBS was added, and $\mathrm{CD} 4{ }^{+} \mathrm{CD} 25^{+}$Tregs were detected by flow cytometry. 
ELISA. ELISA was performed to detect the serum levels of IL-10 (IL-10 ELISA kit; R\&D Systems, Inc., Minneapolis, MN, USA), TGF- $\beta 1$ and TGF- $\beta 2$ (TGF- $\beta 1 / \beta 2$ ELISA kit; R\&D Systems, Inc.) according to the manufacturer's protocol.

Antibody titration assay. Blood samples $(5 \mathrm{ml})$ were collected prior to immunization to establish background antibody levels, and thereafter they were collected every 2 weeks. After the blood samples were allowed to clot at room temperature for $\leq 1 \mathrm{~h}$, they were then centrifuged at $12,000 \mathrm{x} g$ for $5 \mathrm{~min}$. Serum fractions were collected and diluted 10-fold in PBS. Anti-DNP immunoglobulin $\mathrm{G}$ titers were determined by ELISA, as previously described (18). Absorbance was measured at $492 \mathrm{~nm}$ using a 3550 microplate reader (Bio-Rad Laboratories, Inc, Hercules, CA, USA). Best-fit sigmoidal curves were obtained from plotting the absorbance vs. the logarithmic dilution factors using GraphPad Prism 4 (GraphPad Software, Inc., La Jolla, CA, USA). Titer levels were obtained as half maximal effective concentration values from the midpoint of each sigmoidal curve.

DTH scoring. DTH was assessed as previously described (29). After DNP application, swelling and even blistering was observed 12-24 h later, but it resolved within 2-5 days. When swelling was present again 1-2 weeks later, an allergy was suggested, and the swelling was scored as ++++ (diameter, $\geq 20 \mathrm{~mm}$ ) or +++ (diameter, $\geq 15-<20 \mathrm{~mm}$ ). In the event that there was no response within 1-2 weeks, $50 \mu \mathrm{g}$ DNP was reapplied to the lesion, and the response was observed $24 \mathrm{~h}$ later. Swelling was scored as ++ (diameter, $\geq 10-<15 \mathrm{~mm}),+$ (diameter, $<10 \mathrm{~mm}$ ) or negative (in the absence of swelling).

Statistical analysis. Baseline demographic and clinical characteristics are presented as a number and percentage. $\chi^{2}$ tests were used to examine the associations between baseline characteristics and treatment groups. As blood samples were collected at baseline (day 0) and on days 2, 5, 10 and 20, a mixed-effects model was used to evaluate group and time effects on changes in the levels of T cells and inhibitory cytokines by taking into account the repeated measures design. Post-hoc multiple comparisons were made between groups and time points with Bonferroni correction.

OS time was defined as the time elapsed from the date of surgery to the date of mortality. Disease-free survival (DFS) time was defined as the time elapsed from the date of surgery to the date of the first swelling/blistering. To evaluate differences in OS time and DFS time between treatment and DTH response groups, Kaplan-Meier survival analyses were performed. Log-rank tests were conducted to examine differences in OS time and DFS time between the groups. All statistical analyses were performed using SPSS statistical software version 22 for Windows (IBM SPSS, Armonk, NY, USA). A two-tailed P-value of $<0.05$ was considered to indicate a statistically significant difference.

\section{Results}

Baseline demographics and clinical characteristics. There were 36 patients in the treatment group ( 23 male cases and 13 female cases) and 36 cases in the control group (16 male cases and 20 female cases). The mean age of the patients was 60.0 years (range, 29-85 years). As shown in Table I, the majority of the patients were $<70$ years old $(72.2$ and $63.9 \%$ for the DNP monotherapy and combination therapy groups, respectively), and $\sim 1 / 2$ of the patients were diagnosed with stage IV melanoma. All demographic and clinical characteristics were comparable between the monotherapy control and combination treatment groups (all P>0.05; Table I).

Effects of immunotherapy combined with laser therapy on peripheral Treg levels. As shown in Fig. 1, the levels of peripheral Tregs significantly decreased over time in each group $(\mathrm{P}<0.001)$. However, there was no significant difference between the combination therapy groups after considering repeated measurements across time $(\mathrm{P}=0.098)$.

Combination therapy increases IFN- $\gamma$ secretion by $T$ cells and significantly reduces inhibitory cytokine levels. As shown in Fig. 2, patients receiving combination treatment exhibited significantly higher IFN- $\gamma$ production by $\mathrm{CD}^{+} \mathrm{T}$ cells $[\mathrm{F}(1,70)=56.00 ; \mathrm{P}<0.001]$ and $\mathrm{CD}^{+} \mathrm{T}$ cells $[\mathrm{F}(1,70)=86.79$, $\mathrm{P}<0.001]$ than patients receiving DNP monotherapy. Post-hoc multiple comparisons revealed that IFN- $\gamma$ secretion by $\mathrm{CD}^{+}$ $\mathrm{T}$ cells significantly increased in the combination therapy group at days 10 and 20, compared with control group (both $\mathrm{P}<0.001$; Fig. 2A). Similar results were observed with $\mathrm{CD}^{+}$ T cells at days 5, 10 and $20(\mathrm{P}=0.036, \mathrm{P}<0.001$ and $\mathrm{P}<0.001$, respectively; Fig. 2B).

Compared with patients receiving DNP monotherapy, those receiving combination therapy exhibited a significant reduction in the levels of $\mathrm{IL}-10[(\mathrm{~F}(1,70)=341.87, \mathrm{P}<0.001$; Fig. 3A], TGF- $\beta 1[\mathrm{~F}(1,70)=75.33, \mathrm{P}<0.001$; Fig. $3 \mathrm{~B}]$ and TGF- $\beta 2$ $[\mathrm{F}(1,70)=7.65, \mathrm{P}=0.007$; Fig. $3 \mathrm{C}]$, as indicated in Fig. 3 .

Comparisons of survival rates by treatment and DTH response. The 3-year OS rate was $12.2 \%$ in patients receiving DNP and $25.9 \%$ in those receiving combination therapy, with a median survival time of 19.0 and 28.0 months, respectively. Survival time is considered the equivalent of follow-up time. Kaplan-Meier analysis of survival rates revealed that the patients in the combination treatment group experienced significantly longer OS times than those in the monotherapy group ( $\mathrm{P}=0.024$; Fig. 4A). Furthermore, the 1-year DFS rate was 44.0 and $69.1 \%$ in the monotherapy and combination therapy treatment groups, respectively. Log-rank analysis revealed that the patients in the combination therapy group experienced a longer DFS time than those in the monotherapy group (19.0 vs. 12.0 months, respectively; $\mathrm{P}=0.007$; Fig. 4B).

Patients with a DTH response of $\geq 15 \mathrm{~mm}$ experienced a longer OS time than patients with a DTH response of $<15 \mathrm{~mm}$ (30.0 vs. 16.0 months, respectively; $\mathrm{P}<0.001$; Fig. 4C). In addition, log-rank analysis revealed that patients with a DTH response of $<15 \mathrm{~mm}$ experienced a longer DFS time than those with a DTH response of $<15 \mathrm{~mm}$ (20.0 vs. 10.0 months, respectively; $\mathrm{P}=0.001$; Fig. 4D).

Evaluation of safety. No severe adverse events were observed in any of the 72 patients enrolled in the present study. The most common side effects included a low-grade fever and fatigue (Table II). Thus, in situ immunotherapy with DNP in 
Table I. Descriptive statistics of demographic and clinical characteristics in 72 patients with malignant melanoma of the skin treated with monotherapy $(n=36)$ or combination therapy $(n=36)$.

\begin{tabular}{lcc}
\hline Characteristic & DNP, n $(\%)$ & DNP+laser therapy, $(\%)$ \\
\hline Age, years & $26(72.2)$ & $23(63.9)$ \\
$\leq 70$ & $10(27.8)$ & $13(36.1)$ \\
$>70$ & & \\
Gender & $23(63.9)$ & $16(44.4)$ \\
Male & $13(36.1)$ & $20(55.6)$ \\
Female & & \\
Tumor stage ${ }^{a}$ & $11(30.6)$ & $9(25.0)$ \\
IIIb & $7(19.4)$ & $12(33.3)$ \\
IIIc & $18(50.0)$ & $15(41.7)$ \\
IV & & $22(61.1)$ \\
Location of primary lesion & $20(55.6)$ & $14(38.9)$ \\
Skin & $16(44.4)$ & 0.4098 \\
Viscera & & \\
\hline
\end{tabular}

abased on the American Joint Committee on Cancer staging system (24). DNP, dinitrophenyl.

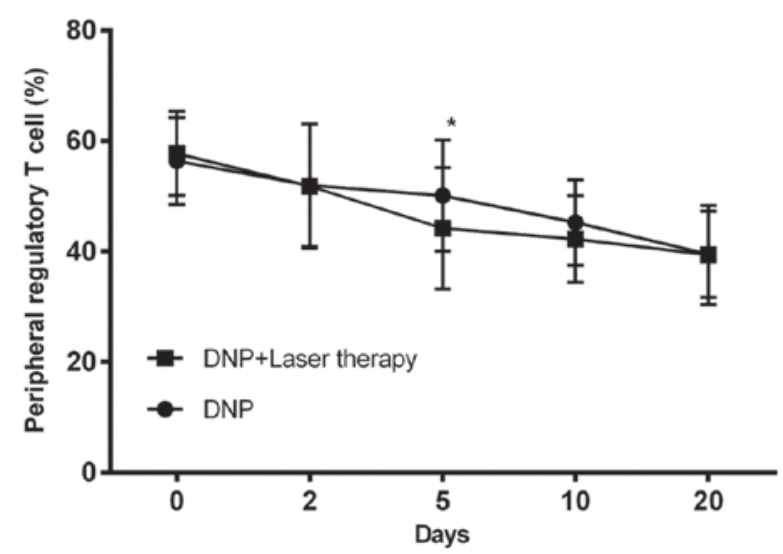

Figure 1. Changes in the number of peripheral Tregs over time. Peripheral Treg levels were measured in patients treated with DNP alone and in those receiving combination therapy. Values are presented as the mean and standard deviation. " $\mathrm{P}<0.05$ for combination therapy vs. monotherapy. Treg, regulatory $\mathrm{T}$ cells; DNP, dinitrophenyl.

combination with laser therapy demonstrated favorable efficacy and an acceptable safety profile.

\section{Discussion}

For the majority of patients with stage IV MM, the survival time is $\leq 1$ year after diagnosis (29) due in large part to the lack of an effective therapy. As MM maintains high immunogenicity (11), the present study aimed to compare the clinical outcomes in MM patients receiving localized immunotherapy to induce DTH via DNP in combination with laser therapy against those observed in patients treated with DNP alone. DNP monotherapy and combination therapy decreased Treg levels over time to a similar extent. However, patients receiving the combination treatment exhibited significantly higher IFN- $\gamma$ production by $\mathrm{CD}^{+}$and $\mathrm{CD} 4^{+} \mathrm{T}$ cells, and significantly

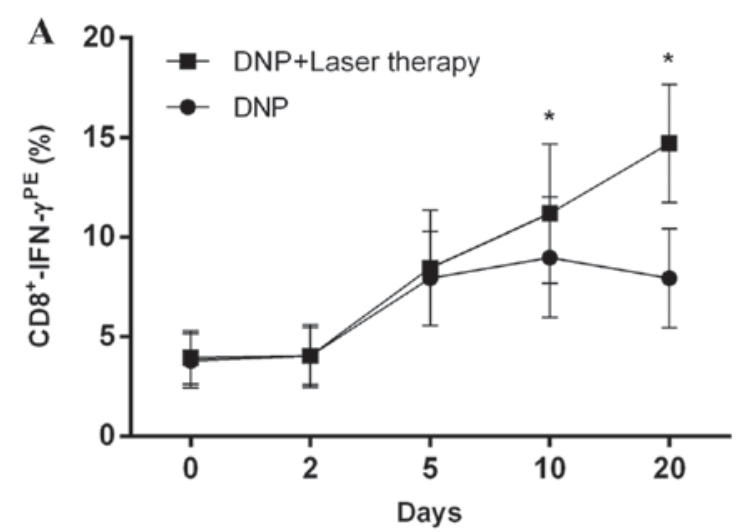

B

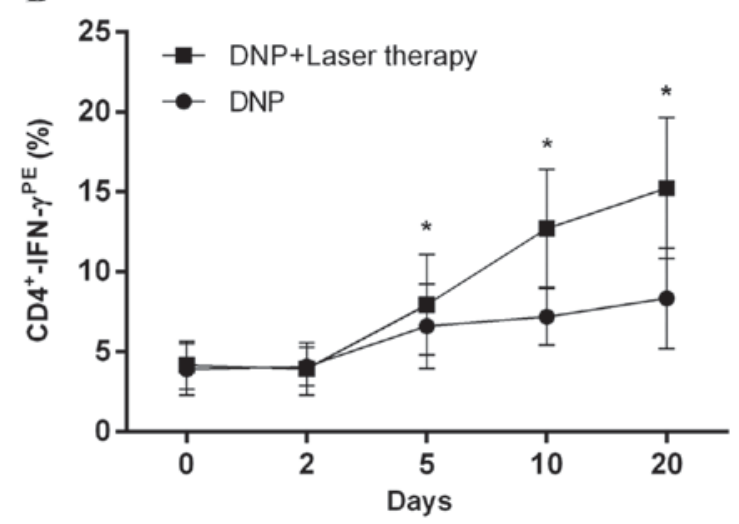

Figure 2. Secretion of INF- $\gamma$ by $\mathrm{CD} 8^{+}$and $\mathrm{CD} 4^{+}$cells. (A) $\mathrm{CD} 8^{+}$and (B) $\mathrm{CD} 4^{+}$ cell secretion of INF- $\gamma$ over time was evaluated by ELISA. Values are presented as the mean and standard deviation. ${ }^{*} \mathrm{P}<0.05$ indicates a significant difference between the two treatment groups for a given time point. IFN, interferon; $\mathrm{CD}$, cluster of differentiation; $\mathrm{PE}$, phycoerythrin.

reduced levels of IL-10, TGF- $\beta 1$ and TGF- $\beta 2$ than the control group. Furthermore, the patients in the combination treatment group experienced significantly longer OS and DFS times than 
Table II. Adverse events in 72 patients with malignant melanoma treated with dinitrophenyl alone or in combination with laser therapy.

\begin{tabular}{|c|c|c|c|c|c|}
\hline \multirow[b]{2}{*}{ Adverse events } & \multicolumn{5}{|c|}{ Grade, $\mathrm{n}$} \\
\hline & 0 & 1 & 2 & 3 & \\
\hline Fever & 56 & 10 & 4 & 2 & \\
\hline Fatigue & 49 & 16 & 5 & 2 & ( \\
\hline Neutropenia & 65 & 4 & 3 & 0 & \\
\hline Nausea, vomiting & 56 & 12 & 4 & 0 & 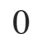 \\
\hline Diarrhea & 67 & 5 & 0 & 0 & \\
\hline Epistaxis & 70 & 1 & 1 & 0 & \\
\hline Hemoptysis or hemafecia & 72 & 0 & 0 & 0 & \\
\hline Increase in blood pressure & 59 & 13 & 0 & 0 & \\
\hline Anemia & 66 & 6 & 0 & 0 & \\
\hline
\end{tabular}

the control group. Given that no severe adverse events were observed in either treatment group, which is consistent with our previous study (30), DNP treatment combined with laser immunotherapy may represent a novel therapeutic strategy for advanced MM. These results are consistent with other previous studies, which reported that laser immunotherapy in combination with immune adjuvant therapy could achieve strong immune responses in MM and breast cancer patients (31-33).

Terheyden et al (34) used dinitrochlorobenzene to induce contact dermatitis, which in combination with DTIC therapy, was used to treat metastatic MM. The objective response rate was $62 \%$ in patients with stage III MM $(n=39)$ and $9 \%$ in those with stage IV MM ( $\mathrm{n}=33)$, and $>50 \%$ of patients remained progression-free for 1 year regardless of the stage of MM (35). In the present study, DNP hapten was used to induce DTH through DNP-mediated activation of T cells. MHC presentation of the hapten by antigen-presenting cells can also induce the production of tumor antigens, which may cause cross-antigen presentation (12). Subsequent hapten-induced presentation of tumor antigens can be recognized by the immune system (13). Cutaneous DTH could be used as an indicator to evaluate immune therapy (35), as well as being a predictor of survival (36). In 27 patients with stage IV MM receiving a DC vaccine to induce $D T H$, the median survival time was 22.9 months $(n=19)$ in DTH-positive patients and 4.8 months in DTH-negative patients (37). Similarly, in the present study, the extent of the DTH reaction was associated with OS and DFS. By contrast, in a study of 284 melanoma patients treated with an autologous tumor cell vaccine in combination with DNP, a positive DTH response $(\geq 5 \mathrm{~mm})$ was not associated with the number of living melanoma cells, but with the number of dead tumor cells (36). Thus, further studies will determine if combination therapy is associated with tumor cell death.

Along with the extent of DTH, combination therapy was associated with increased OS and DSF times in the present study. As local radiotherapy is associated with the regression of metastatic cancer at a distance from the irradiated site, a phenomenon called the abscopal effect may be observed, which may be mediated by a systemic immune response (38).

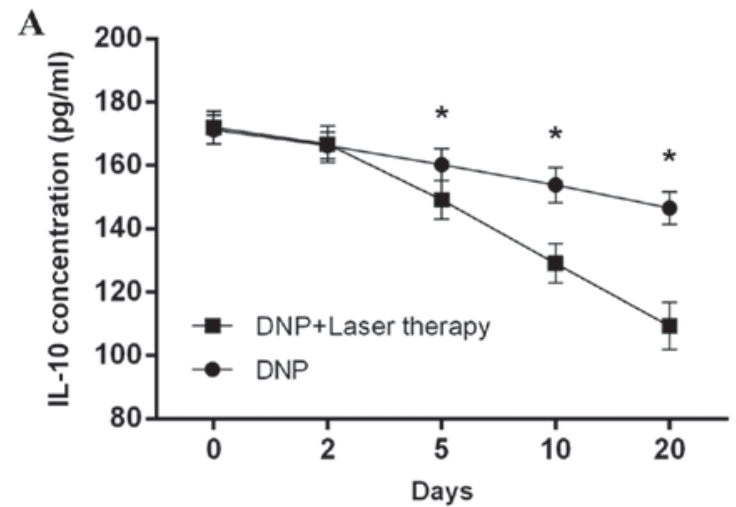

B

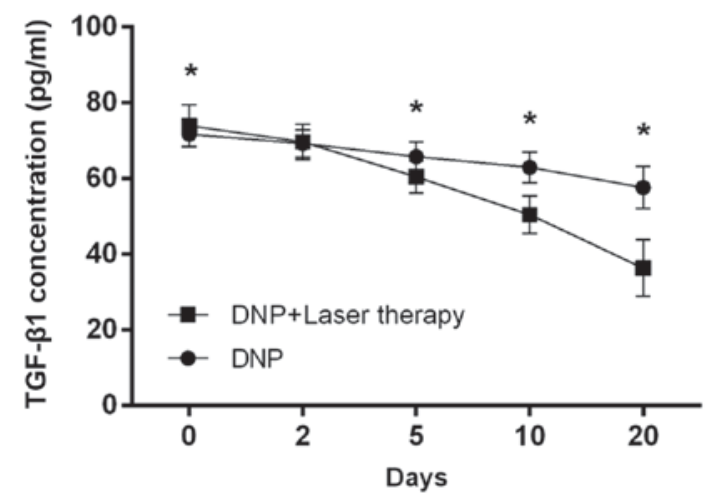

C

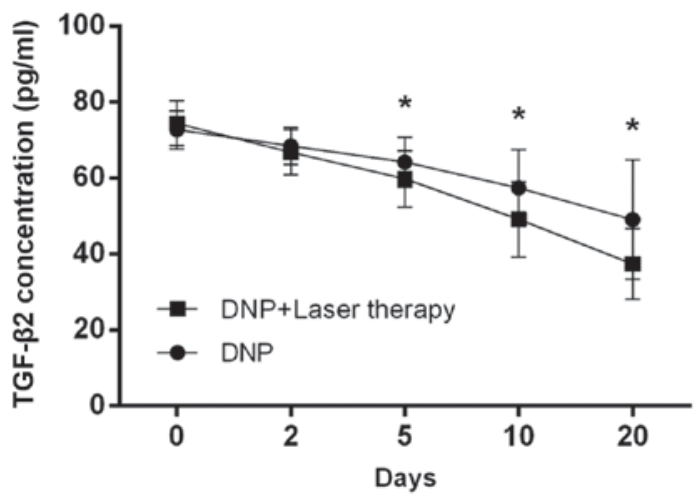

Figure 3. Effects of DNP treatment alone or with laser therapy on serum cytokine levels. Changes in (A) IL-10, (B) TGF- $\beta 1$ and (C) TGF- $\beta 2$ concentrations were evaluated over time by ELISA. Values are presented as the mean and standard deviation. ${ }^{*} \mathrm{P}<0.05$ indicates a significant difference between the two treatment groups for a given time point. DNP, dinitrophenyl; IL, interleukin; TGF, transforming growth factor.

Further studies will assess whether the increased OS and DFS times in patients receiving combination therapy were associated with reduced metastasis.

The extent of DTH induced by chemoimmunotherapy is also consistent with an increase in the proportion of CD8 ${ }^{+}-$IFN- $\gamma^{+}$cells $(39,40)$. In the present study, increased proportions of IFN- $\gamma$-producing $\mathrm{CD}^{+}$and $\mathrm{CD} 4^{+} \mathrm{T}$ cells were observed over time with each treatment; however, the proportions were significantly greater in the patients receiving combination therapy. These results suggested that the extent to which DTH was induced was greater with combination therapy than with monotherapy. 
A

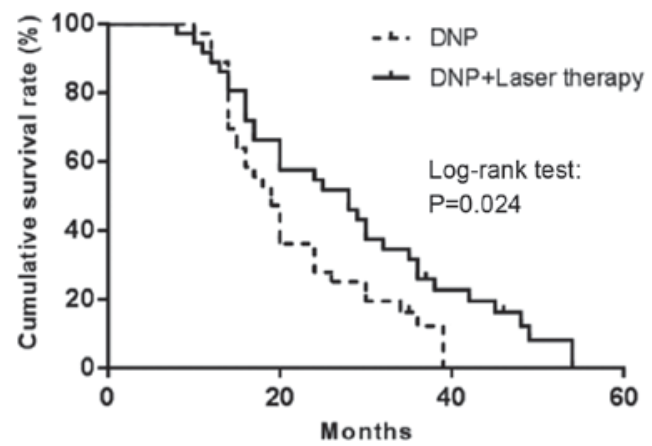

C

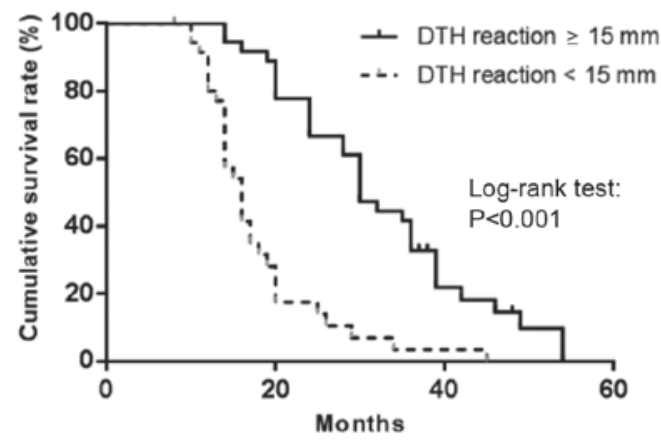

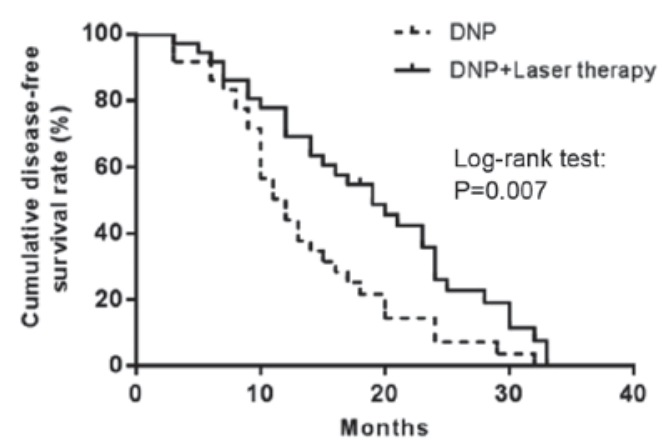

D

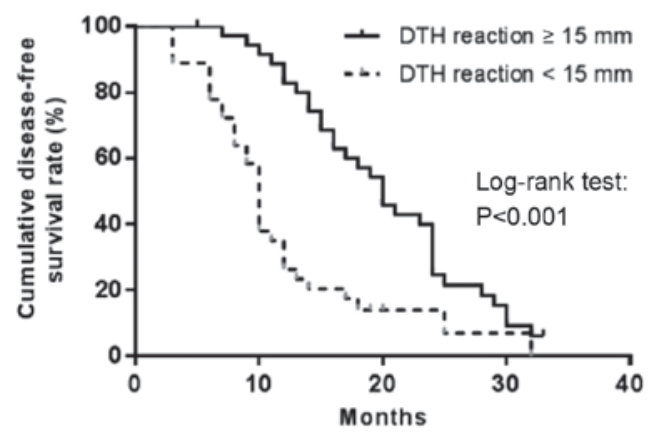

Figure 4. Kaplan-Meier survival curves by treatment and DTH reaction. (A) OS rate and (B) DFS rate by treatment. (C) OS rate and (D) DFS rate by DTH reaction. OS, overall survival; DFS, disease-free survival; DTH, delayed-type hypersensitivity; DNP, dinitrophenyl.

Tregs have an essential role in sustaining self-tolerance and immune homeostasis by suppressing a number of physiological and pathological immune responses, including those in the tumor microenvironment (19). In the present study, the levels of peripheral $\mathrm{CD} 4^{+} \mathrm{CD} 25^{+}$Tregs decreased in the two treatment groups; however, no differences between the groups were noted over time. The decrease in Treg levels coincided with reduced serum levels of inhibitory cytokines, including IL-10, TGF- $\beta 1$ and TGF- $\beta 2$. Furthermore, the suppression of these cytokines was significantly greater in patients receiving combination therapy at days 5, 10 and 20 . These results are consistent with those reported for patients treated with a vaccine consisting of melanoma cells with DNP, in which OS time was reduced in patients with high IL-10 levels in the tumor microenvironment (41).

The present study is limited by its relatively small sample size. Therefore, additional studies with larger numbers of patients and studies taking place at different institutions are necessary to confirm the results of the present study. In addition, the patients in the present study were sensitized to DNP via its topical application; therefore, further studies assessing the possible additive effects of using laser therapy with a previously described DNP-modified melanoma cell vaccine are necessary $(33,40)$. Finally, the mechanism by which combination therapy enhances OS and DFS was not examined. It is possible that the localized treatment impacted the incidence of metastasis or reduced metastatic lesions through the abscopal effect, which will be analyzed in further studies $(38,42)$.

Taken together, the present results indicate that the cutaneous application of DNP may induce a highly specific systemic immune response that can be enhanced with laser therapy. This immune response may reduce the incidence of distant metastases, which may improve the survival time of MM patients. Thus, given that no severe adverse events were observed in either treatment group, DNP treatment combined with laser immunotherapy may represent a novel therapeutic strategy for advanced MM.

\section{Acknowledgements}

The present study was supported in part by grants from the Beijing Municipal Commission of Science and Technology (no. 2131107002213040), the National Natural Science Foundation of China (no. 81000994) and the Beijing Natural Science Foundation (no. 81572953). The authors would also like to thank the Burns Institute of the First Affiliated Hospital of the Chinese PLA General Hospital.

\section{References}

1. Meier F, Will S, Ellwanger U, Schlagenhauff B, Schittek B, Rassner $\mathrm{G}$ and Garbe $\mathrm{C}$ : Metastatic pathways and time courses in the orderly progression of cutaneous melanoma. Br J Dermatol 147: 62-70, 2002.

2. Becker JC, Kämpgen E and Bröcker EB: Classical chemotherapy for metastatic melanoma. Clin Exp Dermatol 25: 503-508, 2000.

3. Garbe C, Peris K, Hauschild A, Saiag P, Middleton M, Spatz A, Grob JJ, Malvehy J, Newton-Bishop J, Stratigos A, et al: Diagnosis and treatment of melanoma: European consensus based interdisciplinary guideline. Eur J Cancer 46: 270-283, 2010.

4. Legha SS, Ring S, Eton O, Bedikian A, Buzaid AC, Plager C and Papadopoulos N: Development of a biochemotherapy regimen with concurrent administration of cisplatin, vinblastine, dacarbazine, interferon alfa, and interleukin- 2 for patients with metastatic melanoma. J Clin Oncol 16: 1752-1759, 1998. 
5. O'Day SJ, Gammon G, Boasberg PD, Martin MA, Kristedja TS, Guo M, Stern S, Edwards S, Fournier P, Weisberg M, et al: Advantages of concurrent biochemotherapy modified by decrescendo interleukin-2, granulocyte colony-stimulating factor and tamoxifen for patients with metastatic melanoma. J Clin Oncol 17: 2752-2761, 1999.

6. Middleton MR, Grob JJ, Aaronson N, Fierlbeck G, Tilgen W, Seiter S, Gore M, Aamdal S, Cebon J, Coates A, et al: Randomized phase III study of temozolomide versus dacarbazine in the treatment of patients with advanced metastatic malignant melanoma. J Clin Oncol 18: 158-166, 2000.

7. Atkins M: The treatment of metastatic melanoma with chemotherapy and biologics. Curr Opin Oncol 9: 205-213, 1997.

8. Legha S, Ring S, Papadopoulos N, Raber M and Benjamin RS A phase II trial of taxol in metastatic melanoma. Cancer 65 2478-2481, 1990.

9. Bedikian A, Weiss G, Legha S, Burris HA III, Eckardt JR, Jenkins J, Eton O, Buzaid AC, Smetzer L, Von Hoff DD, et al: Phase II trial of docetaxel in patients with advanced cutaneous malignant melanoma previously untreated with chemotherapy. J Clin Oncol 13: 2895-2899, 1995.

10. Avril M, Aamdal S, Grob J, Hauschild A, Mohr P, Bonerandi JJ, Weichenthal M, Neuber K, Bieber T, Gilde K, et al: Fotemustine compared with dacarbazine in patients with disseminated malignant melanoma: A phase III study. J Clin Oncol 22: 1118-1125, 2004.

11. Berd D: A tale of two pities: Autologous melanoma vaccines on the brink. Hum Vaccin Immunother 8: 1146-1151, 2012

12. Calalona WJ, Taylor PT, Rabson AS and Chretien PB: A method for dinifrochlorobengene contact sensitigafron: A clinico pathological study. N Engl J Med 286: 399-402, 1972.

13. Fujisawa Y, Nabekura T, Nakao T, Nakamura Y, Takahashi T, Kawachi Y, Otsuka $F$ and Onodera $M$ : The induction of tumor-specific $\mathrm{CD}^{+} \mathrm{T}$ cells via major histocompatibility complex class II is required to gain optimal anti-tumor immunity against B16 melanoma cell line in tumor immunotherapy using dendritic cells. Exp Dermatol 18: 396-403, 2009.

14. Terabe M and Berzofsky JA: Immunoregulatory T cells in tumor immunity. Curr Opin Immunol 16: 157-162, 2004.

15. Somasundaram R, Jacob L, Swoboda R, Caputo L, Song H, Basak S, Monos D, Peritt D, Marincola F, Cai D, et al: Inhibition of cytolytic $\mathrm{T}$ lymphocyte proliferation by autologous $\mathrm{CD} 4^{+} / \mathrm{CD} 25^{+}$ regulatory $\mathrm{T}$ cells in a colorectal carcinoma patient is mediated by transforming growth factor-beta. Cancer Res 62: 5267-5272, 2002

16. Jacobs JF, Nierkens S, Figdor CG, de Vries IJ and Adema GJ Regulatory $\mathrm{T}$ cells in melanoma: The final hurdle towards effective immunotherapy? Lancet Oncol 13: e32-e42, 2012.

17. Wolf AM, Wolf D, Steurer M Gastl G, Gunsilius E and Grubeck-Loebenstein B: Increase of regulatory T cell in the peripheral blood of cancer patients. Clin Cancer Res 9: 606-612, 2003 .

18. Read S, Malmström V and Powrie F: Cytotoxic $\mathrm{T}$ lymphocyte-associated antigen 4 plays an essential role in the function of CD25(+)CD4(+) regulatory cells that control intestinal inflammation. J Exp Med 192: 295-302, 2000

19. Correll A, Tuettenberg A, Becker C and Jonuleit H: Increased regulatory $\mathrm{T}$-cell frequencies in patients with advanced melanoma correlate with a generally impaired T-cell responsiveness and are restored after dendritic cell-based vaccination. Exp Dermatol 19: e213-e221, 2010

20. Ladányi A, Mohos A, Somlai B, Liszkay G, Gilde K, Fejos Z, Gaudi I and Tímár J: FOXP3 ${ }^{+}$cell density in primary tumor has no prognostic impact in patients with cutaneous malignant melanoma. Pathol Oncol Res 16: 303-309, 2010.

21. Lagouros E, Salomao D, Thorland E, Hodge DO, Vile R and Pulido JS: Infiltrative $\mathrm{T}$ regulatory cells in enucleated uveal melanomas. Trans Am Ophthalmol Soc 107: 223-228, 2009.

22. Mougiakakos D, Johansson CC, Trocme E, All-Ericsson C, Economou MA, Larsson O, Seregard S and Kiessling R: Intratumoral forkhead boxP3-positive regulatory $\mathrm{T}$ cells predict poor survival in cyclooxygenase-2-positive uveal melanoma. Cancer 116: 2224-2233, 2010.

23. Mourmouras V, Fimiani M, Rubegni P, Epistolato MC Malagnino V, Cardone C, Cosci E, Nisi MC and Miracco C: Evaluation of tumour-infiltrating $\mathrm{CD}^{+} \mathrm{CD} 25^{+} \mathrm{FOXP} 3^{+}$regulatory $\mathrm{T}$ cells in human cutaneous benign and atypical naevi, melanomas and melanoma metastases. Br J Dermatol 157: 531-539, 2007.

24. Edge SB and A.J.C.o. Cancer, AJCC cancer staging handbook: From the AJCC cancer staging manual. Springer-Verlag, New York Inc, 2010
25. Karnofsky DA, Abelmann WH, Craver LF and Burchenal JH. The use of the nitrogen mustards in the palliative treatment of carcinoma. With particular reference to bronchogenic carcinoma. Cancer 1: 634-656, 1948

26. Eisenhauer EA, Therasse P, Bogaerts J, Schwartz LH, Sargent D, Ford R, Dancey J, Arbuck S, Gwyther S, Mooney M, et al: New response evaluation criteria in solid tumours: Revised RECIST guideline (version 1.1). Eur J Cancer 45: 228-247, 2009 .

27. U.S. Department of Health and Human Services, National Institutes of Health, National Cancer Institute. Common Terminology Criteria for Adverse Events (CTCAE) Version 4.0. Published 28 May 2009 (v4.03: June 14, 2010); cited 14 January 2014. Available from: http://evs.nci.nih gov/ftp1/CTCAE/CTCAE_4.03_2010-2006-14_QuickReference_5x7. pdf

28. Trcka J, Kämpgen E, Becker JC, Schwaaf A and Bröcker EB: Immune chemotherapy of malignant melanoma. Epifocal administration of dinitrochlorobenzene (DNCB) combined with systemic chemotherapy with dacarbazine (DTIC). Hautarzt 49: 17-22, 1998 (In German).

29. Calalona WJ, Taylor PT, Rabson AS and Chretien PB: A method for dinitrochlorobenzene contact sensitization. A clinicopathological study. N Engl J Med 286: 399-402, 1972.

30. Barth A, Wanek LA and Morton DL: Prognostic factors in 1,521 melanoma patients with distant metastasis. J Am Coll Surg 181: 193-201, 1995.

31. Li X, Min M, Gu Y and Du N: Laser immunotherapy: Concept, possible mechanism, clinical applications and recent experimental results. IEEE J Selected Topics Quantum Electronics 18 1434-1438, 2012

32. Li X, Naylor MF, Le H, Nordquist RE, Teague TK, Howard CA, Murray $\mathrm{C}$ and Chen WR: Clinical effects of in situ photoimmunotherapy on late-stage melanoma patients: A preliminary study. Cancer Biol Ther 10: 1081-1087, 2010.

33. Li X, Le H, Wolf RF, Chen VA, Sarkar A, Nordquist RE, Ferguson H, Liu H and Chen WR: Long-term effect on EMT6 tumors in mice induced by combination of laser immunotherapy and surgery. Integrative Cancer Ther 10: 368-373, 2011.

34. Terheyden P, Kortüm AK, Schulze HJ, Durani B, Remling R, Mauch C, Junghans V, Schadendorf D, Beiteke U, Jünger M, Becker JC and Bröcker EB: Chemoimmunotherapy for cutaneous melanoma with dacarbazine and epifocal contact sensitizers: Results of a nationwide survey of the German Dermatologic Co-operative Oncology Group. J Cancer Res Clin Oncol 133: 437-444, 2007

35. Quillien V, Lesimple T and Toujas L: Vaccinal cell therapy in melanoma. Bull Cancer 90: 722-733, 2003 (In French).

36. Berd D, Sato T and Mastrangelo MJ: Effect of the dose and composition of an autologous hapten-modified melanoma vaccine on the development of delayed-type hypersensitivity responses. Cancer Immunol Immunother 51: 320-326, 2002.

37. Ridolfi L, Petrini M, Fiammenqhi L, Granato AM, Ancarani V, Pancisi E, Brolli C, Selva M, Scarpi E, Valmorri L, et al: Dendritic cell-based vaccine in advanced melanoma: Update of clinical outcome. Melanoma Res 21: 524-529, 2011.

38. Stamell EF, Wolchok JD, Gnjatic S, Lee NY and Brownell I: The abscopal effect associated with a systemic anti-melanoma immune response. Int J Radiat Oncol Biol Phys 85: 293-295, 2013.

39. Wack C, Kirst A, Becker JC, Lutz WK, Bröcker EB and Fischer WH: Chemoimmunotherapy for melanoma with dacarbazine and 2,4-dinitrochlorobenzene elicits a specific $\mathrm{T}$ cell-dependent immune response. Cancer Immunol Immunother 51: 431-439, 2002.

40. Kumamoto T, Huang EK, Paek HJ, Morita A, Matsue H, Valentini RF and Takashima A: Induction of tumor-specific protective immunity by in situ Langerhans cell vaccine. Nat Biotechnol 20: 64-69, 2002

41. Mahipal A, Terai M, Berd D, Chervoneva I, Patel K, Mastrangelo MJ and Sato T: Tumor-derived interleukin-10 as a prognostic factor in stage III patients undergoing adjuvant treatment with an autologous melanoma cell vaccine. Cancer Immunol Immunother 60: 1039-1045, 2011.

42. Postow MA, Callahan MK, Barker CA, Yamada Y, Yuan J, Kitano S, Mu Z, Rasalan T, Adamow M, Ritter E, et al: Immunologic correlates of the abscopal effect in a patient with melanoma. N Engl J Med 366: 925-931, 2012. 